\title{
Factors Associated with Food Workers Working while Experiencing Vomiting or Diarrhea
}

\author{
STEVEN SUMNER, ${ }^{1}$ LAURA GREEN BROWN, ${ }^{2 *}$ ROBERTA FRICK, ${ }^{3}$ CARMILY STONE, ${ }^{4}$ L. RAND CARPENTER, ${ }^{5}$ \\ LISA BUSHNELL, ${ }^{6}$ DAVE NICHOLAS, ${ }^{7}$ JAMES MACK, ${ }^{8}$ HENRY BLADE, ${ }^{9}$ MELISSA TOBIN-D'ANGELO, ${ }^{10}$ \\ KAREN EVERSTINE, ${ }^{11}$ AND THE ENVIRONMENTAL HEALTH SPECIALISTS NETWORK WORKING GROUP ${ }^{2}$
}

\begin{abstract}
${ }^{1}$ Duke University Hospital, Medical Research, Room 8254DN, 2301 Erwin Road, Durham, North Carolina 27710; ${ }^{2}$ National Center for Environmental Health, Centers for Disease Control and Prevention, MS F60, 4770 Buford Highway, Atlanta, Georgia 30341; ${ }^{3}$ California Department of Public Health, Food and Drug Branch, 850 Marina Bay Parkway, Building P, First Floor, Richmond, California 94808; ${ }^{4}$ Iowa Department of Public Health, Bureau of Environmental Health Services, 321 East 12th Street, Des Moines, Iowa 50319; ${ }^{5}$ Tennessee Department of Health, 425 Fifth Avenue N., Cordell Hull, First Floor, Nashville, Tennessee 37243; ${ }^{6}$ Connecticut Department of Public Health, Food Protection Program, Division of Environmental Health, MS No. 51 FDP, 410 Capitol Avenue, P.O. Box 340308, Hartford, Connecticut 06134-0308; ${ }^{7}$ New York State Department of Health, Bureau of Community Environmental Health and Food Protection, 547 River Street, Flannigan Square, Room 515, Troy, New York 12180; ${ }^{8}$ Wisconsin Department of Health Services, 1 West Wilson Street, Madison, Wisconsin 53702; ${ }^{9}$ Office of Food Protection, Rhode Island Department of Health, 3 Capitol Hill, Providence, Rhode Island 02908; ${ }^{10}$ Department of Human Resources, Georgia Division of Public Health, 2 Peachtree Street N.W., 14th Floor, Atlanta, Georgia 30303, and ${ }^{11}$ Acute Disease Investigation and Control, Minnesota Department of Health, 625 Robert Street N., P.O. Box 64975, St. Paul, Minnesota 55164, USA
\end{abstract}

MS 10-108: Received 11 March 2010/Accepted 1 October 2010

\begin{abstract}
This study sought to determine the frequency with which food workers said they had worked while experiencing vomiting or diarrhea, and to identify restaurant and worker characteristics associated with this behavior. We conducted interviews with food workers $(n=491)$ and their managers $(n=387)$ in the nine states that participate in the Centers for Disease Control and Prevention's Environmental Health Specialists Network. Restaurant and worker characteristics associated with repeatedly working while experiencing vomiting or diarrhea were analyzed via multivariable regression. Fifty-eight (11.9\%) workers said they had worked while suffering vomiting or diarrhea on two or more shifts in the previous year. Factors associated with workers having worked while experiencing vomiting or diarrhea were (i) high volume of meals served, (ii) lack of policies requiring workers to report illness to managers, (iii) lack of on-call workers, (iv) lack of manager experience, and (v) workers of the male gender. Our findings suggest that policies that encourage workers to tell managers when they are ill and that help mitigate pressures to work while ill could reduce the number of food workers who work while experiencing vomiting or diarrhea.
\end{abstract}

Foodborne disease in the United States is estimated to cause 76 million cases, 325,000 hospitalizations, and 5,000 deaths annually (12). Additionally, surveillance systems at the Centers for Disease Control and Prevention (CDC) estimate that approximately 1,329 foodborne illness outbreaks are reported annually (10). These facts indicate that foodborne illness is a substantial, ongoing problem.

Transmission of pathogens from food workers to the food they handle is implicated as a contributing factor in approximately $20 \%$ of foodborne illness outbreaks (10). The majority $(46 \%)$ of outbreaks in which food workers have been implicated occurred in food service facilities (17). The U.S. Food and Drug Administration (FDA) has focused on three interventions to prevent such transmission in food service facilities: (i) the removal of pathogens from the hands of food workers through effective hand hygiene, (ii) the use of barriers (e.g., gloves) to prevent bare-hand contact with ready-to-eat foods, and (iii) the exclusion of ill food

\footnotetext{
* Author for correspondence. Tel: 770-488-4332; Fax: 770-488-7310; E-mail: 1rg0@cdc.gov.
}

workers from the workplace $(15,18)$. Specifically, the FDA recommends that food workers who are symptomatic with vomiting or diarrhea should be excluded from work (18). Green et al. (7) found that approximately $5 \%$ of surveyed food workers admitted having worked during the previous year while suffering vomiting or diarrhea. However, little is known about the characteristics of workers who work while experiencing vomiting or diarrhea, or the characteristics of their restaurant environment that might promote or prevent such risky behavior. The present study was designed to collect information on these topics.

\section{METHODS}

Participants. This study was conducted by the Environmental Health Specialists Network (EHS-Net), a network of environmental health specialists and epidemiologists focused on the investigation of contributing factors to foodborne illness. EHS-Net is a collaborative project of the CDC, the FDA, the U.S. Department of Agriculture, and state and local health departments in California, Connecticut, New York, Georgia, Iowa, Minnesota, Oregon, Rhode Island, and Tennessee. 
Data collectors (EHS-Net environmental health specialists) contacted randomly selected restaurants in predefined geographical sites in each state via telephone to arrange for an on-site interview with a kitchen manager and at least one food worker. "Restaurants" were defined as establishments that prepare and serve food or beverages to customers but that are not institutions, food carts, mobile food units, temporary food stands, supermarkets, restaurants in supermarkets, or caterers. Only one restaurant from regional or national chains was included per EHS-Net site. Due to a lack of resources, only English-speaking managers and workers were interviewed. Data collection was anonymous.

Data collection. Data collectors conducted a semistructured interview with a kitchen manager and one to three food workers. To increase participation and cooperation, the kitchen manager chose the food worker(s) to be interviewed. Manager interviews lasted approximately $25 \mathrm{~min}$ and assessed restaurant characteristics. Worker interviews lasted approximately $10 \mathrm{~min}$ and assessed practices concerning working while ill and worker characteristics. The restaurant and worker characteristics assessed were ones that existing data suggest might be related to food safety behavior $(1,4-9,13,14)$.

The manager interview collected data on the following restaurant characteristics: ownership (chain, independent); type of restaurant (fast food, other); type of food served (American, international-ethnic-other); the number of food workers employed ( 1 to 5,6 to $10,>10$ ); the number of meals served on busiest day, a measure of volume ( 1 to 100,101 to $300,>300$ ); the presence of policies requiring workers to tell a manager when they are ill, excluding workers experiencing vomiting or diarrhea from working, and requiring a doctor's note from workers returning to work after an illness; how often the establishment has a food worker on-call or available in case a scheduled worker cannot come in (never-rarely, sometimes-often-always); manager experience at the establishment ( $<4$ years, $\geq 4$ years); whether any managers had received food safety training; whether any managers were food safety certified; and whether any food workers had received food safety training.

The worker interview collected data on the following worker characteristics: gender, education (less than high school, at least a high school degree [including community college], at least some college), age in years ( 15 to 20,21 to 30,31 to $40,>40)$, primary language (English, Spanish, other), experience working in food service kitchens ( $<4$ years, $\geq 4$ years), and whether workers got paid when they missed work because of illness (i.e., paid sick leave). The interviewer also asked how many shifts the worker had worked while experiencing vomiting or diarrhea during the past year.

This study was cleared by the CDC's Institutional Review Board and the appropriate boards in the participating EHS-Net states.

Statistical analysis. We conducted bivariate and multivariable logistic regression models to examine associations between potential explanatory factors (restaurant and worker characteristics) and the outcome variable of working while ill. Specifically, the outcome variable was whether the worker had said in his/her interview with study personnel that he/she had worked two or more shifts during the past year while experiencing vomiting or diarrhea. Workers who had worked for less than 1 year's time were included in analyses. Of the 491 food workers interviewed, 4 were excluded from analysis because they were unsure of how many shifts they had worked while experiencing vomiting or diarrhea, and 1 was excluded because he reported 100 episodes of vomiting or diarrhea.

All variables that were statistically significant at $P<0.10$ in bivariate analysis were included in the initial multivariable model.
Additionally, one variable (paid sick leave) that did not meet the significance criterion was included in the model because it was considered a potentially important factor in determining whether food workers work while ill. Examination of variance inflation and tolerance statistics revealed no substantial multicollinearity among these variables. A backward elimination method was used to determine the variables included in the final multivariable model. Relevant interactions between these variables were tested for significance; none was significant, and the interactions terms were not included in the final model.

All regression analyses were conducted with SAS-callable SUDAAN software (PROC RLOGIST, RTI International, Research Triangle Park, NC). Because multiple workers were interviewed in some restaurants, the worker variable was treated as nested in all analyses, as was the state in which data were collected.

\section{RESULTS}

Participants. Participation rate was $66.9 \%$ (426 of 637) of eligible restaurants contacted. The majority of these restaurants were independently owned $(50.8 \%)$, served fast food $(52.6 \%)$, and served an American, non-international menu (77.7\%). The food worker sample included 486 food workers employed at these restaurants; $51.7 \%$ were female, $55.5 \%$ had at least a high school degree, $40.3 \%$ were age 21 to 30 years, $78.0 \%$ said English was their primary language, and $62.8 \%$ had $\geq 4$ years of experience in food service kitchens (see Table 1 for additional data on restaurant and food worker characteristics).

Factors associated with working while experiencing vomiting or diarrhea. Figure 1 presents descriptive data on the number of shifts workers said they had worked while experiencing vomiting or diarrhea over the past year. Almost 12\% (58) said they had worked with either vomiting or diarrhea on two or more shifts.

Bivariate analyses indicated that several restaurant characteristics were significantly associated with working while experiencing vomiting or diarrhea on two or more shifts over the past year (Table 1). Workers in restaurants that served $>300$ meals on their busiest days were more likely to have said they had worked two or more shifts while enduring vomiting or diarrhea than workers were in restaurants that served $\leq 100$ meals on their busiest days. Workers in restaurants without a policy requiring workers to tell managers when they were ill were more likely to have said they had worked while experiencing vomiting or diarrhea than were workers in restaurants with such a policy. On the other hand, workers in restaurants with a policy requiring a doctor's note from workers returning to work after an illness were more likely to have said they had worked while experiencing vomiting or diarrhea than were workers in restaurants without such policies in place. Workers in restaurants that never or rarely had a worker on-call were more likely to have said they had worked while experiencing vomiting or diarrhea than were workers in restaurants that sometimes, often, or always had a worker on-call. Workers in restaurants with managers who had worked in that restaurant for $<4$ years were more likely to have said they had worked while experiencing vomiting or 
diarrhea than were workers in restaurants with managers who had worked in that restaurant for $\geq 4$ years. The characteristics of ownership, type of restaurant, type of food served, number of food workers employed, presence of a policy excluding workers experiencing vomiting or diarrhea from working, manager food safety training, manager food safety certification, and food worker food safety training were not associated with workers having said they had worked while suffering vomiting or diarrhea.

Bivariate analyses of worker characteristics demonstrated that workers with at least a high school degree were more likely to have said they had worked while experiencing vomiting or diarrhea than were workers with at least some college. Workers aged 21 to 30 years and 31 to 40 years were more likely to have said they had worked while experiencing vomiting or diarrhea than were workers aged $\geq 40$ years. Males were more likely to have said they had worked while experiencing vomiting or diarrhea than were females. The worker variables of primary language and experience were not significantly associated with having worked while experiencing vomiting or diarrhea. Workers without paid sick leave were more than twice as likely to have said they had worked while experiencing vomiting or diarrhea, although this association was not statistically significant.

Five variables were included in the final multivariable model $\left(R^{2}=0.087\right)$ (Table 2$)$. Workers in restaurants that served $>300$ meals on their busiest days, did not have a policy requiring workers to tell managers when they are ill, that never or rarely had a worker on-call, and had managers with $<4$ years of experience were more likely to have said they had worked while suffering vomiting or diarrhea. Males were more likely than females were to have said they had worked while experiencing vomiting or diarrhea.

\section{DISCUSSION}

The finding that almost $12 \%$ of interviewed food workers said they had worked two or more shifts while experiencing vomiting or diarrhea in the past year is striking. Ill workers pose a substantial foodborne illness risk, and factors influencing the decision to work while ill are poorly understood. This study is one of the first to begin to examine these factors.

We found that several restaurant characteristics were significantly associated with workers having said they had worked while enduring vomiting or diarrhea. Volume of business had the strongest association with working while experiencing vomiting or diarrhea, with higher-volume restaurants more likely to have workers working while ill. High-volume restaurants are likely to be busy; management in these restaurants might be less likely to send ill workers home because of the negative impact their absences would have on business operations. Similarly, workers in highvolume restaurants might be reluctant to call in sick out of a desire not to leave their busy coworkers shorthanded. Alternatively, it is possible that food workers in highvolume restaurants make more money than food workers in lower-volume restaurants make and are thus more reluctant to call in sick.
Restaurant policies excluding workers with vomiting or diarrhea from working or requiring doctor's notes were not associated with a lower frequency of workers having worked while experiencing vomiting or diarrhea; indeed, at the bivariate level, policies requiring doctor's notes were associated with a higher frequency of this behavior. However, policies that required food workers to tell managers when they were ill were associated with a lower frequency of workers having worked while experiencing vomiting or diarrhea. Some workers might not have sufficient knowledge of foodborne illness and transmission hazards to enable them to make informed decisions about whether or not to work with certain symptoms. Requiring workers to tell managers when they are ill gives managers the opportunity to make this decision, and this could lead to fewer workers working while ill.

Food workers that worked in restaurants with a food worker on-call in case a scheduled worker is unable to work were less likely to have said they had worked while experiencing vomiting or diarrhea. An on-call worker could serve to mitigate the pressures ill workers might feel to work and managers might feel to require ill workers to work. Qualitative data supports this view-food workers and managers have indicated that staff shortages and the lack of back-up employees make it difficult for ill workers not to work (9).

Manager experience in the restaurant was also associated with less working while undergoing vomiting or diarrhea. However, manager certification and food safety training were not associated with this behavior. This could indicate that knowledge about the risk of workers working while ill might not underlie the relationship between manager experience and ill-worker behavior. However, it may also indicate that certification training does not effectively address employee illness. Alternatively, experienced managers might be more skilled at handling staffing issues caused by workers calling in sick, and subsequently be more likely to allow or encourage ill workers to stay home. Alternatively, managers who have been at their restaurant for longer periods likely know their workers better and might be better able to determine the natures of their illnesses and whether they should work. More research is needed to explore this relationship.

The only worker characteristic associated with working while experiencing vomiting or diarrhea was gender-males were more likely to have said they had engaged in this behavior. This finding is consistent with the results of other studies documenting that males are more likely to engage in unsafe food handling behaviors than are females (13).

We found that workers were approximately twice less likely to have said they had worked while suffering vomiting or diarrhea if they had paid sick leave; however, this association was not statistically significant at the bivariate or multivariable levels. Anecdotal evidence and qualitative data suggest that paid sick leave might be an important factor in determining whether food workers work while ill (14). The issue of paid sick leave for food workers merits further investigation. Additionally, research is needed on other income-related measures. For example, in some 
TABLE 1. Restaurant and food worker characteristics associated with workers having said they had worked while experiencing vomiting or diarrhea on two or more shifts in the past year-bivariate analysis

\begin{tabular}{|c|c|c|c|c|c|}
\hline & \multirow[b]{2}{*}{$n$} & \multicolumn{2}{|c|}{ Frequencies } & \multicolumn{2}{|c|}{ Bivariate analysis $^{a}$} \\
\hline & & $n$ & $\%$ & OR $(95 \% \mathrm{CI})$ & $P$ value \\
\hline Restaurant ownership & 486 & & & & 0.495 \\
\hline Chain & & 239 & 49.2 & 1.00 (ref) & \\
\hline Yes & & 253 & 52.6 & 1.00 (ref) & \\
\hline No & & 228 & 47.4 & $1.04(0.60,1.81)$ & \\
\hline Menu & 485 & & & & 0.326 \\
\hline American & & 377 & 77.7 & 1.00 (ref) & \\
\hline International/ethnic/other & & 108 & 22.3 & $0.70(0.34,1.43)$ & \\
\hline$>10$ & & 182 & 37.5 & $1.53(0.79,2.98)$ & 0.209 \\
\hline Meals served on busiest day & 474 & & & & $0.001 *$ \\
\hline $1-100$ & & 72 & 15.2 & 1.00 (ref) & \\
\hline $101-300$ & & 190 & 40.1 & $1.97(0.55,7.10)$ & 0.298 \\
\hline$>300$ & & 212 & 44.7 & $5.02(1.49,16.89)$ & 0.009 \\
\hline \multicolumn{5}{|l|}{$\begin{array}{l}\text { Policy requiring worker to tell manager } \\
\text { when ill }\end{array}$} & $0.019 *$ \\
\hline Yes & & 324 & 68.2 & 1.00 (ref) & \\
\hline No & & 151 & 31.8 & $1.97(1.12,3.45)$ & \\
\hline No & & 196 & 41.4 & $0.46(0.25,0.86)$ & \\
\hline Food worker on-call & 486 & & & & $0.090 *$ \\
\hline Sometimes/often/always & & 161 & 33.1 & 1.00 (ref) & \\
\hline Never/rarely & & 325 & 66.9 & $1.63(0.93,2.85)$ & \\
\hline Manager experience at establishment & 486 & & & & $0.008 *$ \\
\hline$<4 \mathrm{yr}$ & & 230 & 47.3 & $2.15(1.22,3.77)$ & \\
\hline$\geq 4 \mathrm{yr}$ & & 256 & 52.7 & 1.00 (ref) & \\
\hline Manager food safety training & 483 & & & & 0.210 \\
\hline Yes & & 453 & 93.8 & 1.00 (ref) & \\
\hline No & & 30 & 6.2 & $1.93(0.69,5.39)$ & \\
\hline Manager food safety certified & 466 & & & & 0.573 \\
\hline Yes & & 334 & 71.7 & 1.00 (ref) & \\
\hline No & & 132 & 28.3 & $0.84(0.41,1.71)$ & \\
\hline Food workers receive training & 469 & & & & 0.271 \\
\hline Yes & & 386 & 82.3 & 1.00 (ref) & \\
\hline No & & 83 & 17.7 & $1.44(0.75,2.78)$ & \\
\hline \multicolumn{6}{|l|}{ Worker characteristics } \\
\hline Education & 485 & & & & $0.058^{*}$ \\
\hline Less than high school degree & & 72 & 14.8 & $1.29(0.61,2.71)$ & 0.500 \\
\hline
\end{tabular}


TABLE 1. Continued

\begin{tabular}{|c|c|c|c|c|c|}
\hline & \multirow[b]{2}{*}{$n$} & \multicolumn{2}{|c|}{ Frequencies } & \multicolumn{2}{|c|}{ Bivariate analysis $^{a}$} \\
\hline & & $n$ & $\%$ & OR $(95 \% \mathrm{CI})$ & $P$ value \\
\hline $15-20$ & & 75 & 15.4 & $2.12(0.73,6.15)$ & 0.167 \\
\hline $21-30$ & & 196 & 40.3 & $3.59(1.52,8.46)$ & 0.004 \\
\hline Gender & 486 & & & & $0.015 *$ \\
\hline Female & & 251 & 51.7 & 1.00 (ref) & \\
\hline Male & & 235 & 48.3 & $2.05(1.15,3.65)$ & \\
\hline Primary language & 486 & & & & 0.278 \\
\hline$<4 \mathrm{yr}$ & & 181 & 37.2 & $1.12(0.65,1.95)$ & \\
\hline$\geq 4 \mathrm{yr}$ & & 305 & 62.8 & 1.00 (ref) & \\
\hline $\begin{array}{l}\text { Food worker paid if misses work due to } \\
\text { illness (paid sick leave) }\end{array}$ & 471 & & & & 0.110 \\
\hline Yes & & 71 & 15.1 & 1.00 (ref) & \\
\hline No & & 400 & 84.9 & $2.39(0.82,6.98)$ & \\
\hline
\end{tabular}

${ }^{a} \mathrm{OR}$, odds ratio; $\mathrm{CI}$, confidence interval; $* P<0.10$.

restaurants, kitchen staff receive a proportion of the tips earned by the wait staff. It is unlikely that sick leave pay compensates for this income, and it could play a role in workers' decisions to work while ill.

This study has several limitations. First, the findings from this study should not be generalized beyond the restaurants included in the study. Second, the study collected cross-sectional data, which does not allow causal inferences. Third, the study collected self-report data—data in which respondents report on their own behavior to researchers. These data are susceptible to a bias to underreport socially undesirable behaviors, such as working while ill. Fourth, interviewed workers were not chosen randomly; they were chosen by managers, potentially introducing selection bias. Fifth, because of restaurant space limitations, it was not always assured that worker interviews

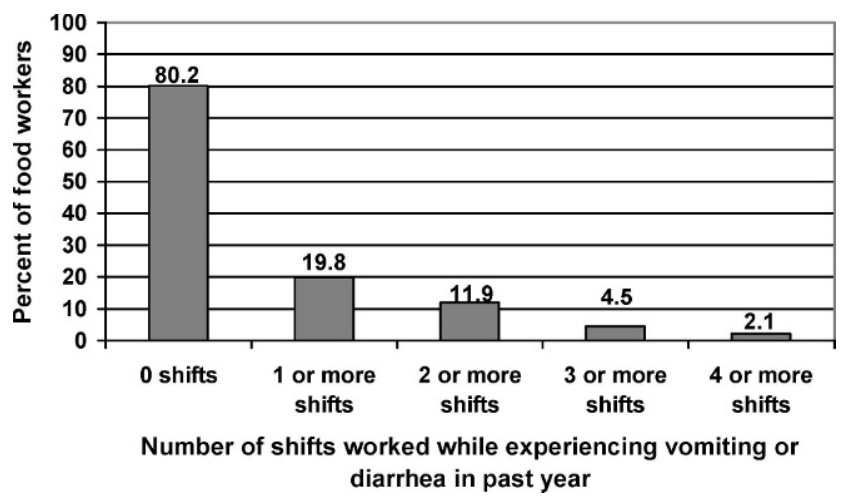

FIGURE 1. Number of shifts workers said they had worked while experiencing vomiting or diarrhea in the past year.
TABLE 2. Restaurant and food worker characteristics associated with workers having said they had worked while experiencing vomiting or diarrhea on two or more shifts in the past yearmultivariable analysis

\begin{tabular}{|c|c|c|}
\hline & \multicolumn{2}{|c|}{ Multivariate analysis $^{a}$} \\
\hline & OR $(95 \% \mathrm{CI})$ & $P$ value \\
\hline \multicolumn{3}{|l|}{ Restaurant characteristics } \\
\hline Meals served on busiest day & & 0.001 \\
\hline $1-100$ & $1.00(\mathrm{ref})$ & \\
\hline $101-300$ & $2.37(0.63,8.97)$ & 0.202 \\
\hline$>300$ & $8.16(2.23,29.86)$ & 0.002 \\
\hline \multicolumn{2}{|l|}{ Policy requiring worker to tell } & 0.002 \\
\hline Yes & 1.00 (ref) & \\
\hline No & $2.72(1.47,5.04)$ & \\
\hline Food worker on call & & 0.084 \\
\hline Sometimes/often/always & 1.0 (ref) & \\
\hline Never/rarely & $1.73(0.93,3.24)$ & \\
\hline $\begin{array}{c}\text { Manager experience at } \\
\text { establishment }\end{array}$ & & 0.030 \\
\hline$<4 \mathrm{yr}$ & $1.96(1.07,3.59)$ & \\
\hline$\geq 4 \mathrm{yr}$ & $1.00(\mathrm{ref})$ & \\
\hline \multicolumn{3}{|l|}{ Worker characteristics } \\
\hline Gender & & 0.016 \\
\hline Female & $1.0 \quad$ (ref) & \\
\hline Male & $2.19(1.16,4.14)$ & \\
\hline
\end{tabular}

${ }^{a} n=437$; OR, odds ratio; CI, confidence interval. 
were performed out of manager hearing distance, which might have affected worker responses. The former three issues would likely result in workers underreporting the frequency with which they had worked while experiencing vomiting or diarrhea. Sixth, workers' perceptions and behavior might differ depending on whether they are primarily experiencing vomiting or diarrhea; the pattern of results may differ for these two symptoms. It is not possible to determine this, because we assessed the frequency of vomiting and diarrhea in only one question. Finally, this study included only English-speaking managers and workers; future research in this area should include non-Englishspeaking managers and workers, as they likely make up a substantial proportion of the food worker population.

Results from this study suggest several potential interventions to reduce the number of food workers who work while experiencing vomiting or diarrhea. In particular, policies that encourage workers to tell managers when they are ill and policies that help mitigate pressures to work while ill show promise and should be investigated further. Investments in such policies may be cost-effective interventions for restaurants, given restaurants' substantial financial losses associated with foodborne disease outbreaks (16). Additional costs to patients and society should be considered and the costs should include those of hospital visits, lost productivity, and permanent disability (11). Given our finding of an increased likelihood that workers in highvolume restaurants will work while ill, such investments could be particularly important for high-volume restaurants.

Although this study focused primarily on examining the link between restaurant characteristics and the behavior of working while ill, multiple factors influence behavior, and there are likely numerous additional factors related to the behavior of interest. These other factors deserve examination, and they include external factors other than those examined here, such as workplace culture (3) and individual characteristics of workers, such as the severity of symptoms, need for income, and attitudes and beliefs (attitudes about work, beliefs about working while ill, etc.).

Not all infectious workers experience symptoms such as vomiting and diarrhea; a proportion of ill workers could continue to spread infectious pathogens while being asymptomatic in a prodromic or convalescent stage (17). This study was not designed to assess this aspect of worker illness, but it is a topic worthy of study. Potential research topics include the effect of duration of work exclusion and/ or assignment to other duties not involving food.

This study offers detailed data on the frequency with which food workers work while experiencing vomiting and diarrhea, and on the factors associated with this behavior. As suggested by our findings, future research and policy endeavors focused on restaurant policies regarding reporting illness to managers and staffing issues could contribute to reductions in the current burden of foodborne illness caused by ill workers.

\section{ACKNOWLEDGMENTS}

This study was conducted by states receiving CDC grant awards funded under CDC-RFA-EH05-013. This publication is based on data collected and provided by the EHS-Net. The contents of this study are solely the responsibility of the authors and do not necessarily represent the official views of CDC.

\section{REFERENCES}

1. Cates, C., M. Muth, S. Karns, M. Penne, C. Stone, J. Harrison, and V. Radke. 2009. Certified kitchen managers: do they improve restaurant inspection outcomes? J. Food Prot. 72:384-391.

2. Centers for Disease Control and Prevention. 2009. Surveillance for foodborne disease outbreaks-United States, 2006. Morb. Mortal. Wkly. Rep. 58:609-615.

3. Clayton, D., and C. Griffith. 2008. Efficacy of an extended theory of planned behaviour model for predicting caterers' hand hygiene practices. Int. J. Environ. Health Res. 18:83-98.

4. Clayton, D., C. Griffith, P. Price, and A. Peters. 2002. Food handlers' beliefs and self-reported practices. Int. J. Environ. Health Res. 12:25-39.

5. Green, L., V. Radke, R. Mason, L. Bushnell, D. Reimann, J. Mack, M. Motsinger, T. Stigger, and C. Selman. 2007. Factors related to food worker hand hygiene practices. J. Food Prot. 70:661-666.

6. Green, L., and C. Selman. 2005. Factors impacting food worker's and managers' safe food preparation practices: a qualitative study. Food Prot. Trends 25:981-990.

7. Green, L., C. Selman, A. Banerjee, R. Marcus, C. Medus, F. Angulo, V. Radke, S. Buchanan, and the EHS-Net Working Group. 2005. Food service workers' self-reported food preparation practices: an EHS-Net study. Int. J. Hyg. Environ. Health 208:27-35.

8. Hedberg, C., J. Smith, E. Kirkland, V. Radke, T. Jones, C. Selman, and the EHS-Net Working Group. 2006. Systematic environmental evaluations to identify food safety differences between outbreak and nonoutbreak restaurants. J. Food Prot. 69:2697-2707.

9. Kendall, P., L. Melcher, and P. Paul. 2000. Factors affecting safe food handling practices in restaurants. Unpublished data.

10. Lynch, M., J. Painter, R. Woodruff, and C. Braden. 2006. Surveillance for foodborne-disease outbreaks-United States, 19982002. Morb. Mortal. Wkly. Rep. 55:1-34.

11. Mauskopf, J., and M. French. 1991. Estimating the value of avoiding morbidity and mortality from foodborne illnesses. Risk Anal. 11:619631.

12. Mead, P., L. Slutsker, V. Dietz, L. McCaig, J. Bresee, C. Shapiro, P. Griffin, and R. Tauxe. 1999. Food-related illness and death in the United States. Emerg. Infect. Dis. 5:607-625.

13. Patil, S., S. Cates, and R. Morales. 2005. Consumer food safety knowledge, practices, and demographic differences: findings from a meta-analysis. J. Food Prot. 68:1884-1894.

14. Patil, S., R. Morales, S. Cates, D. Anderson, and D. Kendall. 2004. An application of meta-analysis in food safety consumer research to evaluate consumer behavior and practices. J. Food Prot. 67:25872595.

15. Ross, M., and J. Guzewich. 1999. Evaluation of risks related to microbiological contamination of ready-to-eat food by food preparation workers and the effectiveness of interventions to minimize those risks. Available at: http://www.fda.gov/Food/FoodSafety/ RetailFoodProtection/ucm210138.htm. Accessed 18 June 2010.

16. Todd, E. 1989. Costs of acute bacterial foodborne disease in Canada and the United States. Int. J. Food Microbiol. 9:313-326.

17. Todd, E. C. D., J. D. Greig, C. A. Bartleson, and B. S. Michaels. 2008. Outbreaks where food workers have been implicated in the spread of foodborne disease. Part 5. Sources of contamination and pathogen excretion from infected persons. J. Food Prot. 71:2582-2595.

18. U.S. Food and Drug Administration. 2009. Food code. Available at: http://www.fda.gov/Food/FoodSafety/RetailFoodProtection/FoodCode/ FoodCode2009/default.htm. Accessed 18 June 2010. 